\title{
Node of Ranvier
}

National Cancer Institute

\section{Source}

National Cancer Institute. Node of Ranvier. NCI Thesaurus. Code C33172.

The gaps formed between myelin sheath segments along axons of certain neurons that serve to facilitate the rapid conduction of nerve impulses. 